\title{
Effect of propranolol on glucose tolerance in hyperthyroidism
}

\author{
A. D. B. HARROWER \\ M.R.C.P.
}

\author{
ISOBEL M. NAIRN \\ B.Sc.
}

\author{
J. A. Strong \\ M.D., F.R.C.P. \\ Department of Medicine and Metabolic Unit, Western General Hospital, Edinburgh
}

\begin{abstract}
Summary
Glucose tolerance tests were performed on six hyperthyroid patients in the morning and afternoon before, and at the end of treatment with propranolol for 2 weeks. All six subjects showed normal glucose tolerance with a normal diurnal rhythm before treatment and this remained normal in five during treatment with propranolol, while one patient developed abnormal glucose tolerance and the diurnal variation was abolished. No change in insulin levels was noted in any of the patients either before or during treatment.

Propranolol may cause deterioration in glucose tolerance in some subjects with hyperthyroidism and this possibility should not be overlooked.
\end{abstract}

\section{Introduction}

The incidence of diabetes mellitus is increased in hyperthyroidism (Wilder, Browne and Butt, 1940; Kreines, Jett and Knowles, Jr, 1965; Kozak, 1971) and, when thyrotoxicosis is corrected, carbohydrate metabolism may revert to normal (Wilder, Browne and Butt, 1940; Kozak, 1971). The $\beta$-adrenergicblocking drug, propranolol, is used widely in the management of thyrotoxicosis (Hadden, Montgomery and Shanks, 1968; Shanks, Hadden and Lowe, 1969; Michie et al., 1974). $\beta$-adrenergic receptor blockade has been shown to inhibit insulin release (Porte, Jr., 1967); such an effect during the treatment of hyperthyroidism could lead to deterioration in carbohydrate metabolism. Alternatively, the clinical improvement with propranolol therapy might also be reflected in an improvement in glucose tolerance. To study these possibilities the authors have investigated the effect of propranolol on glucose tolerance in a group of hyperthyroid patients.

\section{Patients and methods}

Six patients (five female and one male) aged

Correspondence: Dr A. D. B. Harrower, Department of Medicine, Western General Hospital, Edinburgh EH4 2XU. between 32 and 63 years with unequivocal hyperthyroidism gave informed consent to the study (Table 1). Two oral glucose $(50 \mathrm{~g})$ tolerance tests were carried out in each patient and blood was withdrawn at 30 -min intervals for $2.5 \mathrm{hr}$ in each case. The first test was performed in the morning after an overnight fast of $9 \mathrm{hr}$ and the second in the afternoon 4 days later after a similar 9-hr fast. Before the tests, and in the period between, all six subjects were taking a normal diet containing adequate amounts of carbohydrate. The patients then started treatment with propranolol in a dose of $\mathbf{4 0} \mathrm{mg}$ four times daily for a period of 2 weeks when the glucose tolerance tests were repeated in an identical manner in each subject. Blood glucose was analysed by a Technicon autoanalyser using a glucose oxidase method (Hill and Kessler, 1961) and plasma insulin was measured by radioimmunoassay (Hales and Randle, 1963).

\section{Results}

Glucose tolerance was normal in all six subjects before propranolol treatment with the expected diurnal variation and a delayed rise in the blood glucose to a slightly higher peak during the afternoon test (Jarrett et al., 1972) (Fig. 1). During treatment with propranolol, five patients showed no significant change, but glucose tolerance became abnormal in one (No. 3) and the diurnal variation was lost (Fig. 2). Although the mean blood glucose curves during propranolol treatment showed a delay in reaching a peak and were slightly displaced to the right when compared with the curves obtained before treatment, the differences were only significant after $1.5 \mathrm{hr}$ during the morning test $(P<0.05)$ (Fig. 1).

Mean ( \pm s.e.mean) plasma insulin levels during the tests are shown in Fig. 3. The peak values were lower during the afternoon test on both occasions, in keeping with the diurnal rhythm in insulin secretion previously described (Jarret et al., 1972); no significant change occurred during treatment with propranolol.

All six patients showed improvement in clinical 
TABLE 1. Details of age, sex and thyroid function tests in six hyperthyroid patients

\begin{tabular}{cclccc}
\hline Patient & $\begin{array}{c}\text { Age } \\
\text { (years) }\end{array}$ & Sex & $\begin{array}{c}\text { PBI } \\
\text { (mmol/l) }\end{array}$ & $\begin{array}{c}\text { 4-hr uptake of }{ }^{131} \text { I } \\
\%\end{array}$ & T $_{\mathbf{3}}$ (ng/ml) \\
\hline 1 & 56 & M & 1157 & $68 \cdot 0$ & $7 \cdot 30$ \\
2 & 63 & F & 846 & $36 \cdot 5$ & $7 \cdot 15$ \\
3 & 47 & F & 1104 & $42 \cdot 6$ & $7 \cdot 30$ \\
4 & 35 & F & 1168 & $66 \cdot 3$ & $7 \cdot 30$ \\
5 & 32 & F & 1114 & $44 \cdot 4$ & $6 \cdot 79$ \\
6 & 38 & F & 1477 & $65 \cdot 6$ & $7 \cdot 30$ \\
Normal range & & $236-630$ & $5-20$ & $1 \cdot 4-3 \cdot 0$ \\
\hline
\end{tabular}

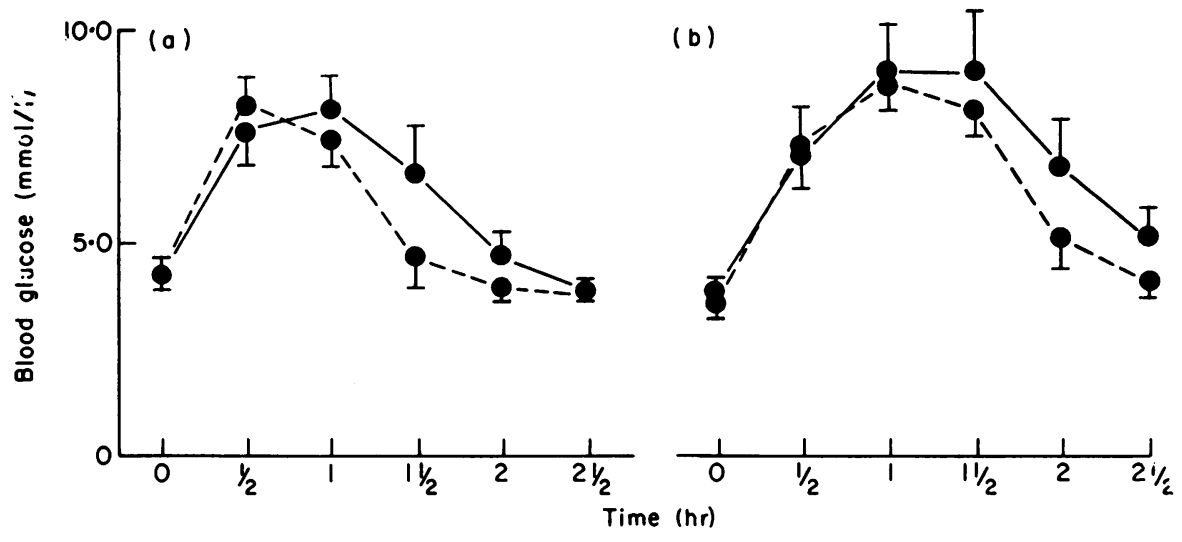

Fig. 1. Blood glucose levels (mean \pm s.e.mean) during glucose tolerance tests commencing at $0700 \mathrm{hr}$ (a) and $1600 \mathrm{hr}$ (b) before and after treatment with propranolol for 2 weeks. ---0 , before propranolol; -0 , after propranolol. $n=6$ in both tests.

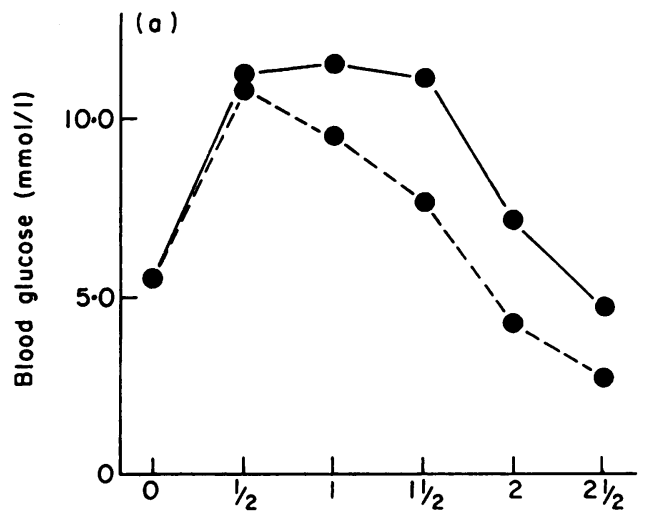

(b)

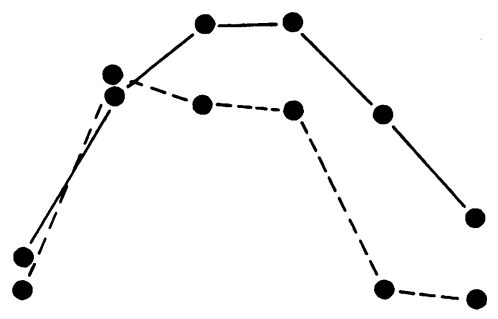

Time $(h r)$

Fig. 2. Blood glucose levels (mean \pm s.e.mean) during glucose tolerance tests commencing at $0700 \mathrm{hr}$ (a) and $1600 \mathrm{hr}$ (b) in a hyperthyroid patient before and after treatment with propranolol for 2 weeks. , before propranolol; - 


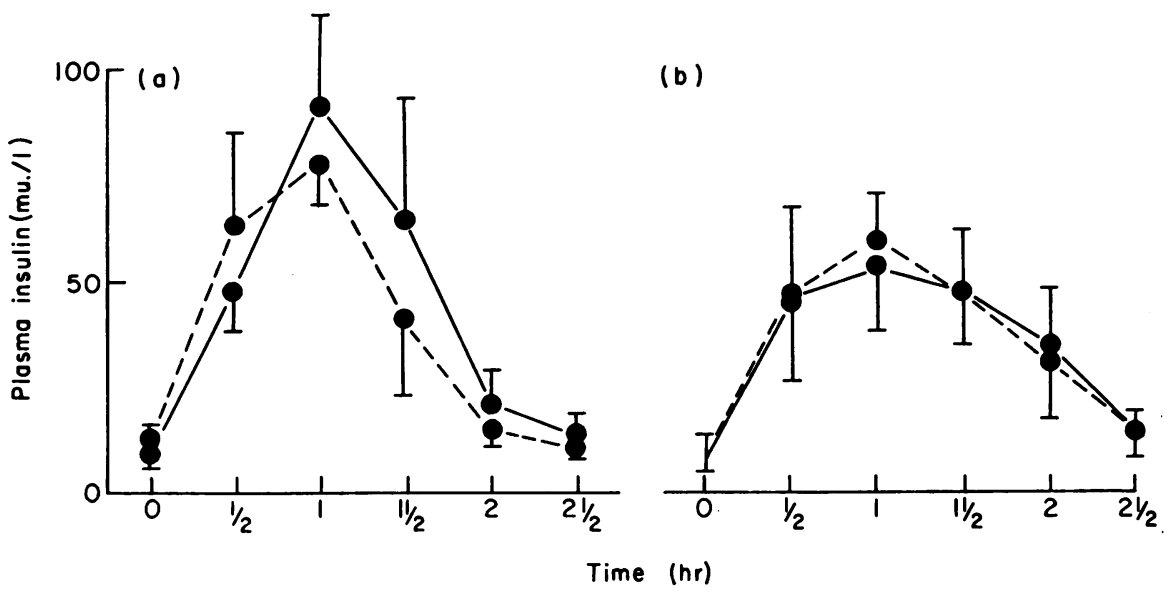

FIG. 3. Plasma insulin levels (mean \pm s.e.mean) during glucose tolerance tests commencing at $0700 \mathrm{hr}$ (a) and $1600 \mathrm{hr}$ (b) before and after treatment with propranolol for 2 weeks. ---0 , before propranolol; -1 , after propanolol. $n=6$ in both tests.

features such as tachycardia and tremor during treatment.

\section{Discussion}

Diabetes mellitus has been reported in $2 \cdot 0-3 \cdot 3 \%$ of hyperthyroid patients (Joslin and Lahey, 1928; Wilder et al., 1940; John, 1942; Allen, Lahey and Murphy, 1947) and abnormal glucose tolerance tests have been described in $57 \%$ of untreated hyperthyroid patients (Kreines, et al., 1965). As $\beta$ adrenergic receptor blockade has been shown to inhibit insulin release (Porte, Jr, 1967) the administration of the drug to hyperthyroid patients who may already have impaired glucose tolerance might have been expected to cause further deterioration with loss of diurnal rhythm of glucose tolerance or even the development of diabetes mellitus.

In all six of the patients glucose tolerance including diurnal rhythm was normal before treatment and, although treatment with propranolol caused a delay in the rise of blood glucose both in the morning and afternoon tests, glucose tolerance and the diurnal pattern remained normal except in one subject. This patient (No. 3) developed impaired glucose tolerance during treatment and loss of diurnal variation. It would seem, therefore, that deterioration in glucose tolerance rather than improvement during treatment with propranolol is more likely to occur.

Despite previous experimental evidence in nondiabetic subjects of reduced insulin secretion in response to glucose infusion with concurrent propranolol administration (Cerasi, Effendi and Luft, 1969) such an effect in hyperthyroid patients could not be demonstrated. This is possibly because the concentration of drug reaching the pancreatic islets after oral administration in the dosage used is low compared to the effect of a constant infusion and any reduction in insulin secretion is likely to be significant in the majority of patients. Indeed, in the subject in whom propranolol produced abnormal glucose tolerance, insulin levels were unaltered, suggesting an extra pancreatic site. The effect of hyperthyroidism on the metabolic clearance rate of propranolol might also be important in modifying the action of the drug in individual patients.

In view of the clinical benefits of the drug in hyperthyroidism, any possible change in glucose tolerance is unlikely to be a serious contra-indication to treatment with propranolol in the majority of patients, although this might not apply to patients with both diabetes and hyperthyroidism.

\section{References}

Allan F.N., Lahey, F.H. \& MurPhy, R. (1947) Hyperthyroidism and diabetes. An evaluation of antithyroid drugs. Transactions of the American Association for the Study of Goitre, 248.

Cerasi, E., EFFEndi, S. \& LufT, R. (1969) Role of adrenergic receptors in glucose-induced insulin secretion in man. Lancet, if, 301.

HADDEN, D.R., Montgomery, D.A.D. \& Shanks, R.G. (1968) Propranolol and iodine-131I in the treatment of thyrotoxicosis. Lancet, ii, 852.

HILl, J.B. \& KessLeR, G. (1961) An automated determination of glucose utilising a glucose oxidase-peroxidase system. Journal of Laboratory and Clinical Medicine, 57, 970.

JARRETT, R.J., BAKER, I.A., KEEN, H. \& OAKLEY, H.W. (1972) Diurnal variation in oral glucose tolerance; blood sugar and plasma insulin levels, morning, afternoon and evening. British Medical Journal, 1, 199. 
JoHN, H.J. (1942) Repeated glucose tolerance tests in hyperthyroidism. Journal of Clinical Endocrinology and Metabolism, 2, 264.

Joslin, E.P. \& LAHEY, F.H. (1928) Diabetes and hyperthyroidism. American Journal of Medical Science, 176, 1.

KozaK, G.P. (1971) In: Joslin's Diabetes Mellitus, 11th edn (Ed. by A. Marble, P. White, R. F. Bradley and L. P. Krall), p. 671. Lea and Febiger, Pennsylvania.

Kreines, K., JeTt, M. \& KNowles, H.C., JR (1965) Observations in hyperthyroidism of abnormal glucose tolerance and other traits related to diabetes mellitus. Diabetes, 14, 740.
Michie, W., Hamer-Hodges, D.W., Pegg, C.A.S., OrR, F.G.G. \& BewSHER, P.D. (1974) Beta-blockade and partial thyroidectomy for thyrotoxicosis. Lancet, i, 1009.

PORTE, D., JR (1967) $\beta$-adrenergic stimulation of insulin release in man. Diabetes, 16, 150.

Shanks, R.G., Hadden, D.R. \& Lowe, D.C. (1969) Controlled trial of propranolol in thyrotoxicosis. Lancet, $\mathbf{i}, 993$.

WILDER, R.M., BROWN, H.C. \& BUTT, H.R. (1940) Incidence of diabetes mellitus in hyperthyroidism. Archives of Internal Medicine, 65, 390.

YALES, C.N. \& RANDLE, P.J. (1963) Immunoassay of insulin with insulin antibody precipitate. Biochemical Journal, 88, 137. 